\title{
Teoria em Cena: a Produção de Vídeo como Instrumento no Ensino de Contabilidade
}

\begin{abstract}
Resumo
Aproveitar o interesse e a experiência dos estudantes com o uso de tecnologias, para alcançar os objetivos de aprendizagem em um curso, é um desafio para os educadores. A produção de vídeo por estudantes é um método de ensinoaprendizagem que envolve recursos tecnológicos e exige uma postura ativa do discente no processo de aprendizagem. Essa atividade pode auxiliar no desenvolvimento de habilidades e competências necessárias à formação do contador, como, por exemplo, pensar conceitualmente, relacionar teoria e prática, e exercer criatividade e liderança. O objetivo desta pesquisa é, nesse sentido, analisar a percepção dos estudantes quanto à utilidade da produção de vídeos como um mecanismo de ensino-aprendizagem na disciplina Teoria da Contabilidade. Participaram da pesquisa 65 alunos matriculados nessa disciplina, no segundo semestre letivo de 2015, em uma universidade pública mineira. Os resultados da pesquisa sugerem que, na percepção dos estudantes, a produção de vídeos tornou o conteúdo da disciplina mais interessante, instigou a criatividade para utilizar os conceitos, além de desenvolver habilidades como comprometimento com o grupo, organização, planejamento, dinamismo, criatividade, proatividade, interpretação e autoaprendizagem. Conclui-se que o método é oportuno e recomenda-se a sua continuidade como didática no ensino de Teoria da Contabilidade e outros conteúdos.
\end{abstract}

Palavras-chave: Produção de vídeos; Teoria da Contabilidade; Tecnologia de ensino.

\section{Ana Maria Beatriz Sardela}

Bacharel em Ciências Contábeis pela Universidade Federal de Uberlândia (UFU) e Auxiliar Administrativo. Contato: Av. Cel. Belchior de Godoi, 310, Goiás, Araguari/ MG, CEP: 38442-204.

E-mail: anambs22@yahoo.com.br

\section{Patrícia de Souza Costa}

Doutora pela Universidade de São Paulo (FEA/USP) e Professora na Universidade Federal de Uberlândia (UFU). Contato: Av. João Naves de Ávila, 2.121, Bloco F, Sala 1F 215, Santa Mônica, Uberlândia/MG, CEP: 38408-294.

E-mail: patrícia.costa@ufu.br

\section{Gilvania de Sousa Gomes}

Mestre em Administração pela Universidade Federal de Uberlândia (UFU) e Professora na Universidade Federal de Uberlândia (UFU). Contato: Av. João Naves de Ávila, 2.121, Bloco F, Sala 1F 215, Santa Mônica, Uberlândia/MG, CEP: 38408-294.

E-mail: gilvaniasg@ufu.br 


\section{Introdução}

A tecnologia se tornou elemento significativo no ambiente universitário (Goode, 2010) e os estudantes estão imersos em um contexto com alta disponibilidade de recursos, tanto dentro como fora das salas de aula. Com o rápido progresso tecnológico, as novas gerações de estudantes, conhecidas por geração Y (nascidos ente 1960 e 1980) e geração Z, identificadas como nativos digitais (nascidos entre 1990 e 2010), estão sempre conectados à internet, fazendo uso intensivo de recursos tecnológicos (Castanha \& Castro, 2010). Assim, o desafio, para os educadores no ensino superior é aproveitar o interesse e a experiência dos alunos com a tecnologia para alcançar os objetivos de aprendizagem de um curso (Engin, 2014). Dessa forma, faz-se necessário discutir a inclusão de tais recursos no processo de ensino-aprendizagem para atrair a atenção dos estudantes (Castanha \& Castro, 2010).

A produção de vídeos por estudantes é um método de ensino-aprendizagem que envolve recursos tecnológicos e exige uma postura ativa do discente no processo de aprendizagem (Engin, 2014). Esse método faz com que o estudante pesquise e compreenda o tema abordado, tendo que simplificar a informação, resumir, sintetizar as partes relevantes de um assunto - o que exige uma postura crítica e responsável no aprendizado (Engin, 2014). Posto isso, criar vídeos viabiliza aos educandos possibilidades para construir e reconstruir o seu aprendizado, podendo auxiliar no desenvolvimento da criatividade e das habilidades de liderança; de trabalho em equipe; de comunicação; de pensar crítica e conceitualmente; e de relacionar teoria e prática (Silva \& Oliveira, 2010; Holtzblatt \& Tschakert, 2011; Engin, 2014).

As aulas podem se tornar mais dinâmicas com a preparação de vídeos, ao reduzir o número de aulas expositivas e permitir que os estudantes pesquisem e desenvolvam atividades fora da sala de aula (Holtzblatt \& Tschakert, 2011). Para Holtzblatt e Tschakert (2011). Essa estratégia pode trazer diversos benefícios ao ensino da Contabilidade, tais como: auxílio aos alunos na memorização de conceitos-chave, ligando-os à experiência prática; melhoria nas habilidades de comunicação e persuasão; favorecimento a uma maior acomodação dos diversos estilos de aprendizagem; e aumento da motivação e entusiasmo dos alunos. Para os autores citados, a estratégia de preparação de vídeos atinge os níveis cognitivo e emocional do estudante, impactando fortemente a motivação e a aprendizagem afetiva. A produção de vídeos tem, ainda, a capacidade de envolver os alunos, estimular um forte interesse em um tópico, ativar estados emocionais e facilitar a absorção e o processamento de informações (Marshall, 2002).

A elaboração de vídeos é uma estratégia adequada para o ensino-aprendizagem de conteúdos tanto práticos quanto teóricos (Sargent, Borthick, \& Lederberg, 2011). Segundo Sargent et al. (2011), tal atividade pode ser útil na redução da ansiedade dos estudantes quanto aos conteúdos relacionados com a matemática, no processo de ensino-aprendizagem da contabilidade, a fim de tornar o aprendizado do conteúdo prático da contabilidade mais fácil e motivador, bem como para desenvolver, nos estudantes, a habilidade de pensar conceitualmente, e construir um alicerce conceitual sólido no aprendizado da Teoria da Contabilidade. Desse modo, desde o início do curso, nas disciplinas introdutórias de Contabilidade, o pensamento conceitual poderia ser desenvolvido com a produção de vídeos (Sargent et al. 2011).

Assim, em disciplinas essencialmente teóricas, como a disciplina Teoria da Contabilidade, o uso da produção de vídeos poderia tornar as aulas mais dinâmicas, interessantes e didáticas, beneficiando alunos e professores. Nessa disciplina, obrigatória no curso de Ciências Contábeis, desde a publicação da Resolução no 732/1992 (CFC, 1992), são apresentados conceitos, teorias, controvérsias e princípios da contabilidade. Na oportunidade, o aluno é instigado a pensar, conceitual e criticamente, habilidades que podem ser desenvolvidas durante a construção dos vídeos.

Diante desse contexto, o objetivo desta pesquisa é analisar a percepção dos alunos quanto à utilidade da produção de vídeos no processo de ensino-aprendizagem da disciplina Teoria da Contabilidade. A percepção dos estudantes foi obtida por meio de um levantamento realizado com 65 alunos do sexto período do curso de Ciências Contábeis de uma universidade pública mineira, no segundo semestre letivo de 2015. 
Esta pesquisa é relevante por avaliar a percepção dos alunos sobre o uso da produção de vídeos como mecanismo de ensino-aprendizagem, sendo um sinalizador de eficácia na abordagem de conteúdos teóricos da Contabilidade e por verificar se há acréscimo de vantagens na formação prática do aluno (como, por exemplo, no desenvolvimento de habilidades de trabalho em grupo, organização e distribuição de tarefas). Com base em seus resultados, espera-se contribuir com a literatura por meio da ampliação das discussões acerca de estratégias que produzem melhorias na aprendizagem de Contabilidade. Além disso, a percepção dos estudantes, quanto à eficácia e resultados da aplicação do método, pode apontar um caminho alternativo quando se almeja o desenvolvimento de habilidades e competências relevantes para a formação do profissional contábil.

\section{Revisão da Literatura}

\subsection{A tecnologia e o ensino de Teoria da Contabilidade}

As pessoas que pertencem às gerações $Y$ e $Z$ cresceram sob grande influência da tecnologia, pois conhecem as inovações e, até mesmo, auxiliam outras pessoas no uso desses novos recursos tecnológicos, como smartphones, tablets, notebooks (Castanha \& Castro, 2010). Para Castanha e Castro (2010), em relação ao processo de ensino-aprendizagem com modelos educativos centrados no professor, muitas dessas pessoas, principalmente da geração Y, não apresentam bons resultados e demonstram apatia na realização das atividades sugeridas pelos educadores. Por isso, quando os professores se valem de ferramentas tecnológicas, conhecidas e utilizadas pelos alunos no dia a dia, eles conseguem se aproximar dos estudantes, despertando neles o interesse pelas atividades desenvolvidas em sala de aula.

Ainda na perspectiva dos autores, a geração Y vive em um mundo imediato, conectada o tempo todo, obtendo as mais diversas informações de que necessita a partir dos recursos tecnológicos disponíveis e do fácil acesso aos meios de comunicação. Sendo assim, não será possível que o educador desconsidere os avanços tecnológicos e as mudanças geracionais existentes e desconsidere estratégias diferenciadas que criem um espaço de comunicação entre aluno e professor (Castanha \& Castro, 2010).

Para Engin (2014), o ensino, por meio dos vários dispositivos tecnológicos, faz com que os alunos se tornem ativos no processo de aprendizagem, tendo eles a responsabilidade de pesquisar parte do conteúdo estudado. Dahawy, Tooma e Kamel (2005) acreditam que o uso de tecnologia da informação e a comunicação na sala de aula permite que os alunos aprendam no seu próprio ritmo, pois eles terão mais tempo e flexibilidade para utilizarem o material, liberdade para tomar iniciativa, o que despertará criatividade no processo de aprendizagem. Esses autores destacam, também, que o uso da tecnologia nas salas de aula faz com que os alunos aprendam a trabalhar em conjunto.

Segundo Machado, Vieira e Meirelles (2012), Castanha e Castro (2010) e Silva e Oliveira (2010), o modo como a aula é planejada pelo professor e como ela acontece é o que desperta determinado grau de interesse nos alunos, sendo necessária a utilização de métodos de ensino que se fundamentam nos recursos tecnológicos da informação e comunicação e na intenção de tornar o ensino mais condizente com a realidade dos nativos digitais.

É oportuno, também, que os professores mesclem diversos métodos de ensino para atrair os alunos, pois, segundo Neves Júnior e Rocha (2010), nenhuma pessoa é igual a outra, possuindo diferentes estilos de aprendizagem que merecem a atenção dos educadores. Para os autores, o conhecimento obtido por meio dos diversos métodos de ensino leva os alunos a aproveitar as estratégias de aprendizagem empregadas pelos professores, para o desenvolvimento de habilidades e competências que podem ser requeridas pelo mercado de trabalho no futuro. 
Machado et al. (2012) acreditam que o uso das tecnologias, dentro da sala de aula, transforma o ensino, muitas vezes, teórico e descontextualizado, em um processo mais dinâmico e prazeroso. Com isso, o uso da tecnologia no ensino da disciplina Teoria da Contabilidade pode ser adequado, por ela ser uma disciplina essencialmente teórica, o que pode mitigar dificuldades no entendimento e na interpretação dos procedimentos e das normas contábeis, reduzindo, também, a falta de interesse dos alunos, por ser uma disciplina que exige mais atenção, concentração e leitura (Campos, Machado, \& Rech, 2015).

Percebe-se, portanto, que estudantes e professores podem ganhar com o uso de tecnologias no processo de ensino-aprendizagem da disciplina Teoria da Contabilidade, uma vez que esse método pode despertar a criatividade e a motivação dos educandos no desenvolvimento das atividades e no estudo do conteúdo da disciplina.

\subsection{Produção de vídeos como estratégia de ensino-aprendizagem}

Para Leal e Cornachione Júnior (2006), a escola é o lugar onde o estudante pode vivenciar e ter contato com problemas e questões elaboradas, despertar o raciocínio crítico e aprender a ser criativo. No curso de Ciências Contábeis, a disciplina Teoria da Contabilidade tem o papel de instigar os alunos a refletir, buscando desenvolver o pensamento crítico e incentivando-os a expor e confrontar suas ideias com outros pontos de vista (Campos et al., 2015).

Silva e Oliveira (2010) acreditam que a produção de vídeos auxilia no desenvolvimento de habilidades diversificadas na formação do estudante, sendo uma ferramenta pedagógica que produz aprendizados de forma significativa, motivadora e dinâmica. Para essas autoras, os recursos midiáticos, em especial, o vídeo, despertam a criatividade ao mesmo tempo em que constroem aprendizados múltiplos, em conformidade com a sensibilidade e as emoções dos alunos.

A produção de vídeos, então, como uma ferramenta de ensino-aprendizagem, faz com que o estudante tenha uma compreensão profunda do conteúdo do curso, despertando o pensamento crítico e a vontade de explorar (Engin, 2014). Ao abordar um tema, por meio da produção de vídeo, esse terá que aprender o conteúdo para passar seu conhecimento e entendimento para quem está assistindo (Engin, 2014).

Nesse contexto, a produção de vídeo está associada ao desenvolvimento da ideia de responsabilidade assumida pelos estudantes, na construção coletiva de um produto, em que o professor tenha o papel de mediador ao orientar os grupos (Pereira \& Rezende Filho, 2013). A produção de vídeo possibilita que o estudante tenha mais autonomia no processo de aprendizagem e que o professor auxilie os estudantes na interação com a atividade proposta e entre os pares (Almeida, 2013).

Segundo Vargas, Rocha e Freire (2007), apesar de a produção de vídeos digitais estar relacionada com entretenimento e diversão, ela pode ser utilizada como atividade de ensino-aprendizagem com alto potencial educacional. Os autores salientam os principais benefícios educacionais que podem ser alcançados com esse método: 
- aperfeiçoamento do pensamento crítico: desenvolve uma base analítica necessária para que o aluno se torne mais observador e crítico em relação aos produtos desse tipo de mídia;

- promoção da expressão e da comunicação: os alunos envolvidos nessa atividade tendem a perder a vergonha e ampliar suas formas de discussão, ou seja, ao estar em um grupo, o aluno precisa expor suas opiniões e entrar em cena para desenvolver a atividade;

- favorecimento de uma visão interdisciplinar: o processo de produzir vídeos traz uma atividade em que os alunos aprendam de forma interdisciplinar, flexível e prática e não apenas teórica, ou seja, faz com que o aluno transmita o seu entendimento sobre o assunto, e não fique apenas como ouvinte passivo;

- integração de diferentes capacidades e inteligências: a produção de vídeos desperta habilidades, como: inteligência linguística, lógico-matemática, musical, espacial, corporal-sinestésica, interpessoal e intrapessoal; e

- impulsionar o trabalho em grupo: valoriza a interação social, a participação e a iniciativa dos alunos, demandando uma boa convivência entre eles.

A criação de vídeos pode auxiliar no desenvolvimento de habilidades e competências requeridas para o exercício da profissão contábil (Holtzblatt \& Tschakert, 2011). Para Costa, Santana, Brounbeck e Gomes (2016), as habilidades mais apropriadas à formação do profissional contábil são: capacidade de determinar diversas alternativas de soluções para problemas reais; interpretar cenários; consolidar vários conteúdos da disciplina e do curso e associá-los com a prática; e desenvolvimento de senso crítico e de responsabilidade individual pelo próprio aprendizado. Percebe-se que a atividade de produção de vídeos pode auxiliar no aprimoramento dessas habilidades.

Além das habilidades citadas, Martin, Evans e Foster (1995) destacam, também, que o método de produção de vídeos exige um maior grau de participação ativa e de concentração do que os métodos tradicionais, como, por exemplo, a aula expositiva. A produção de vídeos faz com que o estudante pesquise o tema, busque bibliografias, compreenda, simplifique, avalie e selecione as informações relevantes, o que os força a sair da zona de conforto e a assumir a responsabilidade pela sua própria aprendizagem (Engin, 2014). Para Engin (2014), o processo de pesquisa, coleta e explicação das informações sobre determinado tema é parte fundamental no desenvolvimento do conhecimento.

Algumas habilidades e competências podem ser desenvolvidas ao longo do processo de criação de vídeos. Vargas et al. (2007) dividem esse processo em três etapas: 1) pré-produção, que consiste na preparação, no planejamento e no projeto do vídeo a ser produzido; 2) produção, que se constitui nas filmagens das cenas que irão compor o vídeo; e 3) a pós-produção, que consta da finalização do vídeo, com a edição e a organização das cenas. Pereira e Rezende Filho (2013) assinalam, também, que, nesse processo, os alunos recorrem espontaneamente a elementos não obrigatórios, como, por exemplo, música e dramatização, que fazem parte de sua cultura e tornam o vídeo mais atrativo, mostrando que essa atividade desperta a criatividade e o entusiasmo no aprendizado.

Almeida (2013), ao investigar a produção de vídeos na sala de aula, concluiu que os alunos, além da resolução das exigências propostas pela atividade, desenvolvem também habilidades de organização, negociação no grupo e busca de soluções para questões inesperadas. Nessa linha de pensamento, Vargas et al. (2007) concluíram que o uso do vídeo desperta motivação nos alunos; promove a perda da timidez e aumento da autoconfiança; instiga o trabalho em equipe, e faz com que os alunos saiam da rotina de agentes passivos no processo de ensino-aprendizagem. Tal assertiva é confirmada por Malheiros, Lima e Mariani (2016, p. 1088), ao referir-se à função lúdica do vídeo como forma de motivação e envolvimento tida como "fonte de prazer e o proveito se torna indispensável e motivador para os expectadores, sendo uma condição sine qua non para que ocorra a aprendizagem". 
Além da função lúdica, apontada por Malheiros et al. (2016), a produção de vídeos ainda possui funções informativa (ao retratar realidades); avaliadora (a autoavaliação decorre de poder ver-se como os outros o veem, permitindo identificar vícios, comportamentos, expressões e outros pontos de melhoria); motivadora (possibilidade de estimulação, sensibilização e provocação do público); e expressiva (o vídeo retrata a manifestação de visões, desejos e sentimentos de seus autores).

Na Tabela 1 é apresentado um resumo das habilidades e competências que podem ser desenvolvidas com a produção de vídeo, de acordo com a literatura.

Tabela 1:

Habilidades e competências que podem ser desenvolvidas com a produção de vídeos

\begin{tabular}{ll}
\hline \multicolumn{1}{c}{ Habilidades e Competências } & \multicolumn{1}{c}{ Fonte } \\
\hline Dinamismo & Silva e Oliveira (2010) \\
\hline Autonomia no processo de aprendizagem & Almeida (2013) \\
\hline $\begin{array}{l}\text { Memorização de conceitos-chave, ligando esses conceitos à } \\
\text { experiência prática. }\end{array}$ & Holtzblatt e Tschakert (2011) \\
\hline Compartilhar o aprendizado & Engin (2014) \\
\hline Compreensão do conteúdo & Engin (2014) \\
\hline Comunicação & Vargas et al. (2007) \\
\hline Concentração & Martin et al. (1995) \\
\hline Criatividade & Silva e Oliveira (2010), Pereira et al. (2013) \\
\hline Estimular um forte interesse em um tópico & Marshall (2002) \\
\hline Facilitar a absorção e o processamento de informações. & Marshall (2002) \\
\hline Interação entre pares e trabalho em grupo & Vargas et al. (2007), Almeida (2013) \\
\hline Interdisciplinaridade & Vargas et al. (2007) \\
\hline Motivação e entusiasmo & Vargas et al. (2007), Silva e Oliveira (2010), \\
\hline Negociação e liderança & Pereira et al. (2013), Malheiros et al. (2016) \\
\hline Participação ativa & Almeida (2013) \\
\hline Pensamento critico & Martin et al. (1995), Vargas et al. (2007) \\
\hline Pesquisa & Vargas et al. (2007), Engin (2014) \\
\hline Responsabilidade pelo aprendizado, autoaprendizagem & Engin (2014) \\
\hline
\end{tabular}

Fonte: elaborada pelas autoras.

Em suma, o uso de produção de vídeos pode proporcionar uma expansão de saberes nos estudantes, fazendo com que o processo de ensino-aprendizagem se torne atrativo e permita-lhes interagir mais em sala de aula, despertando, inclusive, habilidades de organização e planejamento.

\section{Aspectos Metodológicos}

A estratégia de produção de vídeos foi empregada como atividade avaliativa a duas turmas que cursavam a disciplina Teoria da Contabilidade, ministrada no sexto período do curso de Ciências Contábeis de uma universidade pública mineira, no segundo semestre letivo de 2015. Ressalta-se que o curso de Ciências Contábeis, da universidade objeto de estudo, tem duração de cinco anos, ou seja, dez semestres. 
Para a realização da atividade denominada Teoria em Cena, os discentes, no início do semestre, reuniram-se em grupos de três ou quatro componentes e escolheram um tema, dentre aqueles que seriam discutidos na disciplina Teoria da Contabilidade (qualquer tema relacionado na ementa ou no plano de curso), para pesquisarem e elaborarem um vídeo. Ao longo do semestre, em datas especificadas, os grupos deveriam entregar as seguintes atividades: 1) tema, justificativa e relevância; 2) pesquisa bibliográfica e cronograma para o desenvolvimento do vídeo; 3) roteiro; 4) primeira versão; e 5) versão final do vídeo. Cada atividade foi avaliada pelo professor da disciplina e discutida com os grupos em reuniões quinzenais de orientação. Os estudantes utilizaram recursos próprios (celular, câmera, local, material de edição, etc.) para desenvolverem os vídeos.

A versão final do vídeo de cada grupo foi apresentada para ambas as turmas em uma sessão única no anfiteatro da faculdade. Após a entrega da atividade pelos grupos e antes da distribuição das notas, foi aplicado um questionário (Apêndice A) para coletar a percepção dos estudantes sobre o uso dessa metodologia de ensino.

O levantamento foi realizado por meio de um questionário estruturado em três partes (Apêndice A). Na primeira parte, caracterizou-se o perfil dos respondentes (Tabela 2). Participaram da pesquisa 65 estudantes, sendo 43 (66\%) do sexo feminino e 22 (34\%) do sexo masculino; 34 do turno integral (52\%); e 31 (48\%) do turno noturno. A maioria dos discentes (56) estavam matriculados no sexto período do curso, período em que é ministrada a disciplina Teoria da Contabilidade. Além disso, a maior parte da amostra (78\%) estava trabalhando quando respondeu ao questionário. A idade média dos estudantes não se difere estatisticamente.

Tabela 2:

\section{Caracterização dos respondentes}

\begin{tabular}{|c|c|c|c|c|c|c|}
\hline & \multirow{2}{*}{ Itens } & \multicolumn{4}{|c|}{ Períodos } & \multirow{2}{*}{ Total } \\
\hline & & Sexto & Sétimo & Oitavo & Outros & \\
\hline \multirow{4}{*}{ Gênero } & Feminino & 36 & 3 & 4 & 4 & 43 \\
\hline & $\%$ da amostra & $55 \%$ & $5 \%$ & $6 \%$ & $6 \%$ & $66 \%$ \\
\hline & Masculino & 20 & 0 & 1 & 1 & 22 \\
\hline & $\%$ da amostra & $31 \%$ & $0 \%$ & $2 \%$ & $2 \%$ & $34 \%$ \\
\hline \multirow{4}{*}{ Turno } & Integral & 31 & 1 & 2 & 2 & 34 \\
\hline & $\%$ da amostra & $48 \%$ & $2 \%$ & $3 \%$ & $3 \%$ & $52 \%$ \\
\hline & Noturno & 25 & 2 & 3 & 3 & 31 \\
\hline & $\%$ da amostra & $38 \%$ & $3 \%$ & $5 \%$ & $5 \%$ & $48 \%$ \\
\hline \multirow{4}{*}{ Trabalha } & Sim & 43 & 3 & 4 & 4 & 51 \\
\hline & $\%$ da amostra & $66 \%$ & $5 \%$ & $6 \%$ & $6 \%$ & $78 \%$ \\
\hline & Não & 13 & 0 & 1 & 1 & 14 \\
\hline & $\%$ da amostra & $20 \%$ & $0 \%$ & $2 \%$ & $2 \%$ & $22 \%$ \\
\hline
\end{tabular}

Fonte: elaborada pelas autoras

A segunda parte do questionário teve como objetivo identificar a percepção dos estudantes sobre a atividade Teoria em Cena (Tabelas 3 e 4). Nas Tabelas, são evidenciadas as 24 questões sobre a percepção dos estudantes quanto às habilidades e competências desenvolvidas na atividade e sobre os benefícios do desenvolvimento de vídeo na disciplina. Os estudantes atribuíram nota de um, para a total discordância, até dez para a total concordância em cada uma das 24 afirmações. 
Tabela 3:

Questões referentes à percepção sobre a atividade Teoria em Cena

\begin{tabular}{|c|c|}
\hline Considero que o desenvolvimento do Projeto Teoria em Cena... & Atributos \\
\hline 1. Facilitou o entendimento da disciplina. & Entendimento \\
\hline 2. Fez com que eu estudasse mais para desenvolver o projeto. & Estudo \\
\hline 3. Proporcionou maior aplicação dos conceitos teóricos. & Aplicação \\
\hline 4. Contribuiu significativamente para meu melhor desempenho na disciplina. & Desempenho \\
\hline 5. Despertou maior interesse pela disciplina. & Interesse \\
\hline 6. Consegui ampliar meus conhecimentos. & Conhecimento \\
\hline 7. Me tornei mais criativo após o desenvolvimento do projeto. & Criatividade \\
\hline 8. Favoreceu uma maior interação entre meus colegas de sala. & Interação \\
\hline 9. Os resultados do trabalho foram melhores por terem sido desenvolvidos em grupo. & Grupo \\
\hline 10. Potencializou minhas habilidades de trabalhar em equipe. & Equipe \\
\hline 11. Melhorou minha habilidade de comunicação. & Comunicação \\
\hline 12. Fez com que eu desenvolvesse minha capacidade de usar novas tecnologias. & Tecnologia \\
\hline 13. Ajudou-me a desenvolver minha habilidade para resolução de problemas. & Problemas \\
\hline 14. Ajudou-me a desenvolver minhas habilidades de liderança. & Liderança \\
\hline 15. Ajudou-me a desenvolver minhas habilidades de planejamento. & Planejamento \\
\hline 16. Me senti motivado e entusiasmado em participar desta atividade. & Motivação \\
\hline 17. Considero que o projeto é adequado para a disciplina. & Adequado \\
\hline 18. O método contém obstáculos difíceis de vencer. & Dificuldade \\
\hline 19. Fiquei satisfeito com os resultados ao término da atividade. & Satisfação \\
\hline 20. O método é dinâmico. & Dinamismo \\
\hline 21. Proporciona a autoaprendizagem. & Autoaprendizagem \\
\hline $\begin{array}{l}\text { 22. Qual nota você atribui para a utilização de vídeos como estratégia de ensino- } \\
\text { aprendizagem? }\end{array}$ & Utilização \\
\hline $\begin{array}{l}\text { 23. Qual nota você atribui para a atividade Teoria em Cena no processo de ensino- } \\
\text { aprendizagem na disciplina Teoria da Contabilidade? }\end{array}$ & Atividade \\
\hline $\begin{array}{l}\text { 24. Você recomenda que a atividade Teoria em Cena continue a ser aplicada na disciplina } \\
\text { Teoria da Contabilidade? }\end{array}$ & Recomendação \\
\hline
\end{tabular}

Fonte: elaborado pelas autoras.

$\mathrm{Na}$ Tabela 4, estão ilustradas as duas questões dicotômicas e as três questões discursivas contidas no questionário, para que os discentes pudessem descrever aspectos positivos e negativos relacionados ao desenvolvimento da atividade.

Tabela 4:

\section{Questões dicotômicas e discursivas sobre a atividade Teoria em Cena}

\footnotetext{
C. Se eu tivesse oportunidade, eu faria essa atividade novamente? ( ) SIM ( )NÃO

D. Você foi um dos personagens do vídeo do seu grupo? ( )SIM ( )NÃO

Em caso positivo, você se sente mais desinibido sendo filmado ou apresentando trabalhos pessoalmente em sala de aula? Por favor, comente.

H. Em sua opinião, outros benefícios além dos apresentados na sessão anterior do questionário podem ser conseguidos com a aplicação da atividade de vídeos? Se sim, quais?

I. Em sua opinião, quais os pontos positivos da aplicação da atividade de Teoria em Cena na disciplina de Teoria da Contabilidade?

J. Esse espaço é seu! Aproveite e registre suas críticas e sugestões para que possamos aprimorar as próximas versões desta atividade.

Fonte: elaborado pelas autoras.
} 
A terceira parte do questionário teve o objetivo de analisar a autoavaliação dos alunos sobre seu desempenho na realização da atividade Teoria em Cena (Tabela 5). Os estudantes atribuíram nota de um a dez para autoavaliar o seu desempenho e participação.

Tabela 5:

Questões de autoavaliação sobre a atividade Teoria em Cena

\begin{tabular}{l}
\hline 1. Integração e relacionamento com o grupo. \\
\hline 2. Leitura individual extraclasse. \\
\hline 3. Busca por materiais complementares. \\
\hline 4. Proatividade. \\
\hline 5. Comprometimento com as minhas atribuições no grupo. \\
\hline 6. Tempo disponibilizado para a atividade. \\
\hline 7. Uso de atendimento extraclasse aos monitores, professores e mestrandos. \\
\hline 8. Tive uma visão do todo no trabalho. \\
\hline 9. Participei da realização de todas as etapas e atividades do trabalho. \\
\hline
\end{tabular}

Fonte: elaborado pelas autoras.

O questionário aplicado nesta pesquisa foi elaborado com base nos estudos de Martin et al. (1995), Weil, Laswad, Frampton e Radford, (1999), Weil, Oyelere, Yeohe e Firer (2001), Silva e Oliveira (2010), Holtzblatt e Tschakert (2011), Almeida (2013), Pereira e Rezende Filho (2013) e Engin (2014). Para validar o questionário, foi realizado um pré-teste com cinco estudantes e três professores do curso de Ciências Contábeis da universidade objeto de estudo. As sugestões obtidas no pré-teste foram incorporadas ao instrumento. Por questões éticas, foram tomadas medidas de precaução, a fim de preservar a imagem dos respondentes, os quais, livremente, manifestaram consentimento em participar da pesquisa.

A análise dos dados envolveu análise fatorial e foi realizada por meio do programa Statistical Package for the Social Sciences (SPSS). A análise fatorial "é uma técnica multivariada que busca sintetizar as relações observadas entre um conjunto de variáveis inter-relacionadas, buscando identificar fatores comuns" (Fávero, Belfiore, Silva \& Chan, 2009, p. 235). A condução da análise fatorial exige quatro passos, conforme Fávero et al. (2009): 1) análise da matriz de correlações e adequação da utilização da análise fatorial; 2) extração inicial de fatores; 3 ) rotação dos fatores; e 4) interpretação dos fatores. Além disso, na aplicação da análise fatorial deve-se analisar a distribuição de frequência das variáveis por meio do Kaiser-Meyer-Olkin Mesaure of Sampling Adequacy (KMO). O KMO próximo a 0 indica que a análise fatorial pode não ser adequada, pois existe uma correlação fraca entre as variáveis. Por outro lado, quanto mais próximo de 1 o seu valor, mais adequada é a utilização da técnica.

\section{Resultados}

A análise dos resultados foi dividida em três seções, conforme as partes do questionário, de forma que, primeiramente, são evidenciadas as percepções sobre a eficácia do método no desenvolvimento de habilidades e competências, coletadas por meio de questões fechadas. Em seguida, são exibidas as vantagens e desvantagens da produção de vídeos e, por fim, denotadas as respostas da autoavaliação dos estudantes em relação ao seu envolvimento na atividade. 


\subsection{Quanto às contribuições da atividade de produção de vídeos}

Na Tabela 6, são expostas as respostas dos estudantes para as 24 questões apresentadas na Tabela 3 sobre a percepção desses a respeito da estratégia de ensino que utiliza a criação de vídeos. Na percepção dos estudantes, os benefícios da atividade Teoria em Cena, relacionados à busca pessoal pelo conteúdo e conhecimento, típicos da aprendizagem ativa, ocupam a primeira (Estudo) e terceira (Autoaprendizagem) posições no ranking. A satisfação dos alunos com a realização da atividade, apontada como o quinto item mais importante, e a ampliação da obtenção de conhecimentos (Atividade), na sexta posição, reforçam os atributos comentados anteriormente e atestam que o método pode ser útil para um aumento nos níveis de aprendizagem.

Tabela 6:

Ranking da percepção sobre os benefícios da produção de vídeos

\begin{tabular}{|c|c|c|c|c|c|c|c|c|}
\hline Rank & & Atributos & Média & Mediana & Máximo & Mínimo & Moda & Desvio Padrão \\
\hline 1 & 2. & Estudo & 7,57 & 8 & 10 & 2 & 8 & 2,16 \\
\hline 2 & 20. & Dinamismo & 7,48 & 8 & 10 & 1 & 10 & 2,29 \\
\hline 3 & 21. & Autoaprendizagem & 7,43 & 8 & 10 & 1 & 8 & 2,28 \\
\hline 4 & 9. & Grupo & 7,29 & 8 & 10 & 1 & 8 & 2,38 \\
\hline 5 & 19. & Satisfação & 7,25 & 8 & 10 & 1 & 8 & 2,02 \\
\hline 6 & 23. & Atividade & 7,09 & 7 & 10 & 1 & 7 & 1,97 \\
\hline 7 & 22. & Utilização & 7,04 & 7 & 10 & 1 & 8 & 2,12 \\
\hline 8 & 6. & Conhecimento & 7,03 & 7 & 10 & 1 & 7 & 2,3 \\
\hline 9 & 24. & Recomendação & 6,98 & 8 & 10 & 1 & 10 & 2,81 \\
\hline 10 & 10. & Equipe & 6,95 & 8 & 10 & 1 & 8 & 2,36 \\
\hline 11 & 3. & Aplicação & 6,94 & 7 & 10 & 2 & 8 & 2,26 \\
\hline 12 & 17. & Adequação & 6,88 & 7 & 10 & 1 & 5 & 2,3 \\
\hline 13 & 15. & Planejamento & 6,66 & 7 & 10 & 1 & 8 & 2,21 \\
\hline 14 & 8. & Interação & 6,57 & 7 & 10 & 1 & 8 & 2,57 \\
\hline 15 & 11. & Comunicação & 6,46 & 7 & 10 & 1 & 8 & 2,48 \\
\hline 16 & 1. & Entendimento & 6,44 & 6 & 10 & 1 & 8 & 2,51 \\
\hline 17 & 4. & Desempenho & 6,35 & 7 & 10 & 1 & 6 & 2,37 \\
\hline 18 & 13. & Problemas & 6,12 & 7 & 10 & 1 & 7 & 2,43 \\
\hline 19 & 12. & Tecnologia & 6,11 & 6,5 & 10 & 1 & 5 & 2,38 \\
\hline 20 & 14. & Liderança & 6,11 & 6 & 10 & 1 & 5 & 2,42 \\
\hline 21 & 18. & Dificuldade & 6,11 & 6 & 10 & 1 & 10 & 2,85 \\
\hline 22 & 7. & Criatividade & 5,85 & 6 & 10 & 1 & 5 & 2,31 \\
\hline 23 & 5. & Interesse & 5,83 & 6 & 10 & 1 & 6 & 2,53 \\
\hline 24 & 16. & Motivação & 5,62 & 6 & 10 & 1 & 5 & 2,43 \\
\hline
\end{tabular}

Fonte: elaborada pelas autoras.

Ainda se tratando da obtenção de conhecimentos, os atributos que ocupam as sétima e oitava posições no ranking retratam a percepção positiva dos estudantes quanto ao fato de a elaboração de vídeos ser valorosa como método de aprendizagem e ampliação de escopo teórico em relação ao tema estudado. 
Ocupando a quarta e décima posições no ranking das médias, os atributos relacionados ao trabalho em equipe também foram considerados pelos alunos como pontos positivos, já que, segundo eles, houve um melhoramento na capacidade de aprender e criar em grupo (Equipe), além do destaque à quarta posição do ranking à concordância de que os resultados da atividade foram melhores pelo fato de esta ter sido realizada em grupos. Esses resultados revelam, entre outras coisas, que preparar vídeos é uma atividade com potencial de aprimorar habilidades e competências, expande as possibilidades de aquisição de conhecimentos por meio da aprendizagem ativa e contempla os benefícios da colaboração e troca de conhecimentos entre os pares. Tais achados confirmam os estudos de Almeida (2013), Engin (2014) e Vargas et al. (2007).

Quanto à aplicação da metodologia na disciplina Teoria da Contabilidade, as questões 1, 17, 23 e 24 tiveram a finalidade de captar tais percepções. Observa-se que os respondentes manifestaram um juízo positivo sobre os itens, uma vez que a média das notas atribuídas, para cada uma das questões, é superior a cinco. Em termos de importância, as maiores médias atribuídas foram para: a) contribui para a melhoria no processo de ensino-aprendizagem da disciplina Teoria da Contabilidade (questão 23/sexta posição); b) recomenda-se que o método continue a ser empregado na disciplina Teoria da Contabilidade (questão 24/nona posição); c) o método é adequado à disciplina de Teoria da Contabilidade (questão 17/décima segunda posição); e d) facilita o entendimento da disciplina (questão 1/décima sexta posição).

De acordo com a opinião dos alunos, a produção de vídeos, ainda que tenha alcançado médias superiores a 5, é menos útil para despertar o interesse pela disciplina (questão 5/vigésima terceira posição) e, em último lugar em grau de importância, motivou-os a participar da atividade (questão 16/vigésima quarta posição). Ressalta-se que a questão de número 18 (Dificuldade), também, apresentou média acima de cinco (6,11), o que sugere que os estudantes perceberam que o método possuiu obstáculos difíceis de vencer.

Com isso, observa-se que a atividade é uma opção adequada, na percepção dos estudantes, para ser utilizada como método de ensino em disciplinas teóricas, pois facilita o entendimento de uma forma divertida e criativa, fazendo com que o aluno aprofunde os estudos no assunto abordado para melhor transmiti-lo a seus colegas de turma, sendo responsável também por seu próprio aprendizado. Tais resultados estão em linha com as pesquisas de Campos et al. (2015) e Machado et al. (2012), os quais asseveraram que, por conter alta carga teórica, a disciplina Teoria da Contabilidade é um campo fértil para a aplicação de metodologias que tornam as aulas mais dinâmicas e leves.

A atividade serve, da mesma forma, para os alunos interagirem entre si, trocarem ideias e experiências obtidas no desenvolvimento do projeto, e reforçar as habilidades de planejamento e trabalho em equipe, por ser necessário planejar e organizar as fases de desenvolvimento do tema, pré-produção, filmagem, edição e apresentação do vídeo, confirmando o estudo de Vargas et al. (2007).

Apesar de todas as questões registrarem notas médias superiores a 5, as que tiveram maior repetição de nota 5 (Moda) foram: os alunos tornaram-se mais criativos após o desenvolvimento do projeto (7. Criatividade); a atividade possibilitou desenvolver a capacidade de usar novas tecnologias (12. Tecnologia); ajudou a desenvolver habilidades de liderança (14. Liderança); provocou entusiasmo em participar da atividade (16. Motivação); e consideraram que o projeto é adequado para a disciplina (17. Adequação). Quanto à questão sobre o desenvolvimento da capacidade de usar novas tecnologias, a posição do ranking pode ser justificada pelo fato de a maioria dos respondentes da amostra ter idade média de 21 anos, e pertencerem à geração $Z$, também conhecida como nativos digitais, a qual já faz uso intensivo de recursos tecnológicos (Castanha \& Castro, 2010) e, por isso, não representa o desenvolvimento de uma nova habilidade.

Os aspectos de comprometimento, bom relacionamento com o grupo e solução de problemas inesperados corroboram os estudos de Holtzblatt e Tschakert (2011), que identificaram que, para produzir vídeos, o estudante tem que interagir com os outros e trabalhar como uma equipe, a fim de ser bem-sucedido. Almeida (2013) também observou que quando os alunos criam vídeos, estão desenvolvendo habilidades de leitura, organização, negociação em grupo e busca de soluções para questões inesperadas.

Já os aspectos de responsabilidade de participação na realização do trabalho; a busca por materiais complementares; e a responsabilidade pela sua autoaprendizagem coincidem com os achados de Engin (2014), que observou que os alunos estavam preocupados pela procura de materiais a fim da exatidão do 
conteúdo apresentado. Pereira e Rezende Filho (2013), igualmente, identificaram um aumento da responsabilidade assumida pelos estudantes na produção de vídeos; e Silva e Oliveira (2010) corroboram as evidências de que, ao participarem de todas as etapas do trabalho, os alunos constroem e recriam seu próprio conhecimento. Ademais, Martin et al. (1995), do mesmo modo, observaram que o uso da atividade incentiva os alunos a assumirem o controle de sua aprendizagem.

Efetuada a análise dos dados em termos descritivos, procurou-se, mediante a técnica de análise fatorial, examinar se existiriam dimensões subjacentes às variáveis que pudessem sintetizar, resumir as informações nelas contidas, dando à análise dos dados da amostra uma melhor compreensão e profundidade. O primeiro passo para a condução da análise fatorial foi verificar se é adequada a utilização dessa técnica por meio dos testes de KMO e Bartlett's. O KMO de 0,823 torna razoável a aplicação da análise fatorial. O nível de significância do teste de Bartlett's (Chi-square de 53,165; p-value =0,000) evidencia que há correlações entre as variáveis, o que confirma a utilidade dessa análise.

O próximo passo é a extração de fatores da matriz de correção, com a finalidade de encontrar um conjunto de fatores que formem uma combinação linear das variáveis da matriz de correlação. Dessa forma, as variáveis altamente correlacionadas entre si serão combinadas para formar um fator com as demais variáveis da matriz de correlação. Na Tabela 7, têm-se a extração dos componentes principais, dos valores próprios (eigenvalues ou autovalores) para cada fator, bem como os respectivos percentuais de variância explicada.

Tabela 7:

\section{Extração dos fatores}

\begin{tabular}{|c|c|c|c|c|}
\hline Fator & Eigenvalues & \% Variância & Eigenvalues Acumulados & \% Variância Acumulada \\
\hline 1 & 11,511 & 47,962 & 11,511 & 47,962 \\
\hline 2 & 2,189 & 9,121 & 13,700 & 57,084 \\
\hline 3 & 1,644 & 6,852 & 15,345 & 63,936 \\
\hline 4 & 1,244 & 5,183 & 16,588 & 69,118 \\
\hline 5 & 1,166 & 4,858 & 17,754 & 73,976 \\
\hline 6 & 0,871 & 3,631 & 18,625 & 77,606 \\
\hline 7 & 0,712 & 2,967 & 19,338 & 80,573 \\
\hline 8 & 0,585 & 2,438 & 19,923 & 83,011 \\
\hline 9 & 0,566 & 2,358 & 20,489 & 85,369 \\
\hline 10 & 0,540 & 2,252 & 21,029 & 87,621 \\
\hline 11 & 0,485 & 2,022 & 21,514 & 89,642 \\
\hline 12 & 0,477 & 1,988 & 21,991 & 91,630 \\
\hline 13 & 0,356 & 1,484 & 22,347 & 93,114 \\
\hline 14 & 0,291 & 1,214 & 22,639 & 94,328 \\
\hline 15 & 0,251 & 1,045 & 22,890 & 95,373 \\
\hline 16 & 0,240 & 1,002 & 23,130 & 96,374 \\
\hline 17 & 0,206 & 0,858 & 23,336 & 97,232 \\
\hline 18 & 0,179 & 0,746 & 23,515 & 97,978 \\
\hline 19 & 0,120 & 0,499 & 23,635 & 98,477 \\
\hline 20 & 0,097 & 0,405 & 23,732 & 98,883 \\
\hline 21 & 0,087 & 0,361 & 23,819 & 99,244 \\
\hline 22 & 0,081 & 0,336 & 23,899 & 99,580 \\
\hline 23 & 0,060 & 0,249 & 23,959 & 99,829 \\
\hline 24 & 0,041 & 0,171 & 24,000 & 100,000 \\
\hline
\end{tabular}

Fonte: elaborada pelas autoras. 
De acordo com a regra de retenção de fatores com valores de eigenvalues superiores a 1 (Fávero et al., 2009), foram retidos quatro fatores. Examinando-se os eigenvalues, verifica-se que há cinco fatores com valores superiores a 1 que conseguem explicar $73,976 \%$ da variância dos dados originais. O primeiro fator explica 47,962\% dos dados e os demais $9,121 \%, 6,852 \%, 5,183 \%, 4,858 \%$, respectivamente. A análise fatorial final é representada na Tabela 8.

Tabela 8:

\section{Matriz dos fatores após a rotação}

\begin{tabular}{|c|c|c|c|c|c|}
\hline Variáveis & Fator 1 & Fator 2 & Fator 3 & Fator 4 & Fator 5 \\
\hline Entendimento & & 0,783 & & & \\
\hline Estudo & & 0,814 & & & \\
\hline Aplicação & & 0,814 & & & \\
\hline Desempenho & & 0,831 & & & \\
\hline Interesse & & 0,668 & & & \\
\hline Conhecimento & & 0,688 & & & \\
\hline Criatividade & 0,538 & & & & \\
\hline Interação & & & & 0,768 & \\
\hline Grupo & & & & 0,633 & \\
\hline Equipe & & & & 0,674 & \\
\hline Comunicação & 0,646 & & & & \\
\hline Tecnologia & & & & & 0,489 \\
\hline Problemas & 0,653 & & & & \\
\hline Liderança & 0,835 & & & & \\
\hline Planejamento & 0,753 & & & & \\
\hline Motivação & 0,763 & & & & \\
\hline Adequação & & & 0,813 & & \\
\hline Dificuldade & & & & & 0,876 \\
\hline Satisfação & & & & 0,514 & \\
\hline Dinamismo & & & 0,619 & & \\
\hline Autoaprendizagem & & & & 0,511 & \\
\hline Utilização & & & 0,533 & & \\
\hline Atividade & & & 0,743 & & \\
\hline Recomendação & & & 0,858 & & \\
\hline
\end{tabular}

Fonte: elaborada pelas autoras.

Os resultados obtidos mediante a aplicação da técnica de Análise Fatorial, pelo critério varimax normalizada, conforme se observa pela Tabela 8 , evidenciou, no primeiro fator, as variáveis: Criatividade (0,538); Comunicação (0,646); Problemas (0,653); Liderança (0,835); Planejamento $(0,753)$; e Motivação $(0,763)$. A natureza dessas variáveis levaria a inferir que o primeiro fator se referiria principalmente às habilidades relacionais e emocionais. Ressalta-se que esse fator é considerado o mais relevante, já que corresponde por $47,962 \%$ da variância total dos dados (Tabela 7). 
O segundo fator revelou as variáveis: Entendimento (0,783); Estudo (0,814); Aplicação $(0,814)$; Desempenho $(0,831)$; Interesse $(0,668)$; e Conhecimento $(0,688)$. As variáveis parecem estar associadas ao aprendizado e à aplicação prática do conteúdo aprendido. $O$ terceiro fator destacou as variáveis: Adequação (0,813); Dinamismo (0,619); Utilização (0,533); Atividade $(0,743)$; e Recomendação $(0,858)$. A essência dessas variáveis sugere que o terceiro fator está relacionado com os benefícios relacionados à disciplina Teoria da Contabilidade.

As variáveis evidenciadas no quarto fator são: Interação (0,768); Grupo (0,633); Equipe $(0,674)$; Satisfação $(0,514)$; e Autoaprendizagem $(0,511)$. Estas variáveis estão ligadas à aprendizagem colaborativa e a relacionamentos interpessoais. No quinto fator, foram reunidas as variáveis: Tecnologia $(0,489)$; e Dificuldade $(0,876)$. A natureza dessas variáveis leva a inferir que o quinto fator está ligado àquilo que pouco contribuiu em termos de habilidades ou que gerou desconforto.

\subsection{Análise das questões dicotômicas e discursivas}

Na Tabela 9, são apresentadas as respostas dos estudantes para as duas questões dicotômicas C e D, sobre se os alunos fariam a atividade novamente e se foram personagens nos vídeos desenvolvidos, respectivamente. Para os que participaram da encenação do vídeo, perguntou-se, ainda, se eles se sentem mais desinibidos sendo filmados ou apresentando trabalhos pessoalmente em sala de aula.

Observa-se que, na turma do noturno, houve mais estudantes que participaram como personagens do que na turma do turno integral. Com relação ao gênero, constatou-se que $74 \%$ (23) dos que participaram eram meninas e $26 \%$ (8) meninos. Porém, a amostra tinha 43 meninas e 22 meninos, permitindo supor que as meninas têm mais entusiasmo em participar de atividades como esta do que os meninos, que costumam ser mais tímidos. Dos estudantes que foram personagens do vídeo, $81 \%$ trabalham.

Quando questionados se fariam a atividade novamente, 31 discentes responderam que sim, sendo $48 \%$ (15) do turno integral e 52\% (16) do noturno; e desses estudantes que fariam a atividade novamente, $65 \%$ são do gênero feminino e $35 \%$ do gênero masculino, reforçando a ideia de que as meninas preferem mais atividades como essa do que os meninos. Pode-se inferir que, quando os alunos participam ativamente do vídeo produzido, tendo a oportunidade de aproveitar as habilidades que são despertadas no desenvolvimento da atividade, eles percebem os efeitos positivos, por isso, aproveitariam outras oportunidades de repetir tarefas como essa. 
Tabela 9:

Relação entre atuação no vídeo e interesse pela atividade

\begin{tabular}{|c|c|c|c|c|c|c|c|c|c|}
\hline \multirow{2}{*}{\multicolumn{2}{|c|}{ Características dos respondentes }} & \multicolumn{4}{|c|}{ Foi personagem no vídeo? } & \multicolumn{4}{|c|}{ Faria a Atividade Novamente? } \\
\hline & & Sim & $\%$ & Não & $\%$ & Sim & $\%$ & Não & $\%$ \\
\hline \multirow{3}{*}{ Turno } & Integral & 11 & $35 \%$ & 23 & $68 \%$ & 15 & $48 \%$ & 19 & $56 \%$ \\
\hline & Noturno & 20 & $65 \%$ & 11 & $32 \%$ & 16 & $52 \%$ & 15 & $44 \%$ \\
\hline & Total & 31 & $100 \%$ & 34 & $100 \%$ & 31 & $100 \%$ & 34 & $100 \%$ \\
\hline \multirow{3}{*}{ Gênero } & Feminino & 23 & $74 \%$ & 20 & $59 \%$ & 20 & $65 \%$ & 23 & $68 \%$ \\
\hline & Masculino & 8 & $26 \%$ & 14 & $41 \%$ & 11 & $35 \%$ & 11 & $32 \%$ \\
\hline & Total & 31 & $100 \%$ & 34 & $100 \%$ & 31 & $100 \%$ & 34 & $100 \%$ \\
\hline \multirow{3}{*}{ Trabalha } & Sim & 25 & $81 \%$ & 26 & $76 \%$ & 25 & $81 \%$ & 26 & $84 \%$ \\
\hline & Não & 6 & $19 \%$ & 8 & $24 \%$ & 6 & $19 \%$ & 8 & $26 \%$ \\
\hline & Total & 31 & $100 \%$ & 34 & $100 \%$ & 31 & $100 \%$ & 34 & $100 \%$ \\
\hline
\end{tabular}

Fonte: elaborada pelas autoras.

Na Tabela 10, é apresentada a percepção dos estudantes para as habilidades e competências por questões dicotômicas, a fim de verificar se os alunos que atuaram nos vídeos e recomendam a reaplicação da atividade atribuem melhores pontuações às questões da primeira parte do questionário.

Para todos os itens analisados, fica evidente que quem participou como personagem revela visão mais positiva quanto aos benefícios do método e, ainda, aqueles alunos que se sentiriam confortáveis em realizar novamente uma tarefa semelhante conferiram maiores notas aos atributos das vinte e quatro questões. Assim, supõe-se que, quanto maior o grau de envolvimento na atividade, maior a percepção de benefícios decorrentes dela, bem como maior a abertura de interesse para uma nova participação, como um círculo vicioso de aprendizagem ativa: quanto mais se envolve, mais se aprende.

Outrossim, os resultados sinalizam, também, que os estudantes que participaram ativamente do projeto e que gostariam de repetir esse método assinalaram maiores notas ao recomendarem a continuidade da aplicação da atividade Teoria em Cena na disciplina de Teoria da Contabilidade (24. Recomendação) e acreditam que seja adequada a utilização de produção de vídeos como estratégia de ensino-aprendizagem (22. Utilização). 
Tabela 10:

Média dos atributos em relação à participação ativa e disposição em repetir a atividade

\begin{tabular}{|c|c|c|c|c|}
\hline \multirow{2}{*}{ Sigla } & \multicolumn{2}{|c|}{ Faria a atividade novamente? } & \multicolumn{2}{|c|}{ Foi personagem no vídeo? } \\
\hline & Sim & Não & Sim & Não \\
\hline Entendimento & 6,97 & 5,97 & 6,67 & 6,24 \\
\hline Estudo & 7,65 & 7,50 & 7,81 & 7,35 \\
\hline Aplicação & 7,45 & 6,47 & 7,58 & 6,35 \\
\hline Desempenho & 7,03 & 5,74 & 6,94 & 5,82 \\
\hline Interesse & 7,23 & 4,56 & 6,65 & 5,09 \\
\hline Conhecimento & 7,55 & 6,56 & 7,39 & 6,71 \\
\hline Criatividade & 6,48 & 5,26 & 6,23 & 5,50 \\
\hline Interação & 6,87 & 6,29 & 7,32 & 5,88 \\
\hline Grupo & 7,71 & 6,91 & 7,94 & 6,71 \\
\hline Equipe & 7,45 & 6,50 & 7,77 & 6,21 \\
\hline Comunicação & 7,19 & 5,79 & 7,32 & 5,68 \\
\hline Tecnologia & 6,55 & 5,70 & 6,43 & 5,82 \\
\hline Problemas & 6,58 & 5,71 & 6,55 & 5,74 \\
\hline Liderança & 6,94 & 5,35 & 6,68 & 5,59 \\
\hline Planejamento & 7,52 & 5,88 & 7,35 & 6,03 \\
\hline Motivação & 6,90 & 4,44 & 6,35 & 4,94 \\
\hline Adequação & 7,90 & 5,94 & 7,19 & 6,59 \\
\hline Dificuldade & 5,77 & 6,41 & 6,26 & 5,97 \\
\hline Satisfação & 7,61 & 6,91 & 7,90 & 6,65 \\
\hline Dinamismo & 7,97 & 7,03 & 8,00 & 7,00 \\
\hline Autoaprendizagem & 8,03 & 6,88 & 7,77 & 7,12 \\
\hline Utilização & 8,30 & 5,94 & 7,30 & 6,82 \\
\hline Atividade & 8,07 & 6,24 & 7,47 & 6,76 \\
\hline Recomendação & 8,30 & 5,82 & 7,50 & 6,53 \\
\hline
\end{tabular}

Fonte: elaborada pelas autoras.

Ainda, analisando a segunda parte do questionário, na questão discursiva $\mathrm{D}$, questionou-se aos estudantes que participaram como personagens do vídeo se eles se sentiram mais desinibidos sendo filmados ou quando apresentaram trabalhos pessoalmente em sala de aula. Pode-se perceber que 35 deles responderam a esta questão, sendo que: 40\% (14 estudantes) preferem o método de vídeo; 32\% (11 estudantes) preferem apresentar trabalhos pessoalmente em sala de aula; $11 \%$ não se importam com a escolha do método, pois não têm dificuldade em se apresentarem; e 17\% (6 estudantes) preferem não se apresentar, pois são tímidos.

Alguns estudantes relataram que preferem o método de produção de vídeo por terem a opção de refazer a gravação e corrigir erros, ler o roteiro novamente e editarem quantas vezes forem necessárias. Um dos estudantes afirmou: "Particularmente, não tenho dificuldades em apresentar em sala. Porém prefiro filmagem. Se errar, gaguejar tem como fazer de novo. O nervosismo é menor". Outra aluna comentou: "Prefiro ser filmada, porque não tem público na hora da gravação". Nota-se, então, que a atividade de vídeo é passível de correção antes de ser submetida à apresentação e avaliação, e permite ao aluno ler e reler o roteiro quantas vezes forem necessárias antes de gravar, pois precisará ter domínio do que está falando no momento em que está atuando nos vídeos. 
Essa atividade favorece também aqueles estudantes com maiores dificuldades de falar em público presencialmente, pois ao gravar um vídeo, o aluno se sente mais à vontade, já que, no momento da gravação, não está na frente de muitas pessoas. Por outro lado, há alunos que não se sentem à vontade sendo filmados, preferindo a apresentação em sala de aula, como nos seguintes relatos: "Prefiro apresentações pessoais, vídeo não me deixa à vontade". Podem-se destacar, também, expressões como "dá muito trabalho fazer vídeos", "não me sinto à vontade na frente de uma câmera", e ainda, "não me sinto bem me vendo em vídeo e ouvindo minha voz gravada".

Existem alunos cujo grau de timidez não lhes permite sentir-se tranquilos em relação a nenhum dos métodos, como se observa nas narrativas: "Nenhuma das duas situações. Tenho pânico em apresentar de qualquer forma que seja" e "não me sinto desinibida sendo filmada e muito menos apresentando pessoalmente trabalhos, pelo motivo de vergonha se errar ou gaguejar". Para aqueles alunos muito tímidos, qualquer que seja o método de apresentação pública é um grande desafio.

Há, além disso, alunos sem restrições a aparições em público, o que ocorre, normalmente, com pessoas extrovertidas e com facilidade de comunicação públicas, como relatam dois estudantes: "Não tenho dificuldades em apresentar em sala de aula, portanto, não tive diferença" e "Independente da ocasião, não vejo problemas em apresentação".

Na questão G, exibida na Tabela 3, perguntou-se se os estudantes recomendam que a atividade continue a ser aplicada na disciplina de Teoria da Contabilidade, atribuindo uma nota de um a dez, como demonstrado na Tabela 3 (24. Recomendação), e, em caso negativo, foi solicitada uma justificativa para a resposta. Verificou-se que as maiores restrições em relação ao desenvolvimento da atividade estão ligadas à dificuldade de locomoção física para as reuniões de grupo, requeridas para o desenvolvimento da atividade. Isso pode ter relações com o fato de a maioria dos estudantes que responderam ao questionário trabalharem e/ou estudarem em turno noturno.

A questão discursiva $\mathrm{H}$, exposta na Tabela 4, solicita que o aluno discorra sobre outros benefícios que podem ser conseguidos com produção de vídeos, além dos já relacionados anteriormente no questionário. Os principais comentários foram: "outros benefícios seriam uma maior interação com a turma" e outros ainda reforçaram a ideia da criatividade, discutida por Leal e Cornachione Júnior (2006), conforme o relato: "Na minha opinião o principal benefício é usar a imaginação para aplicar os conceitos (...)", e, mais: “(...) outro ponto positivo é o exercício da criatividade e o uso da tecnologia para o desenvolvimento do trabalho".

Outro participante também destaca os benefícios: "Criatividade, trabalho em grupo e para quem é tímido ajuda na 'desinibição". Também foram ressaltadas outras vantagens como: "aprendemos a fazer planejamentos, dividir tarefas, e estudamos mais para a apresentação". Ressalta-se, então, que os benefícios mais mencionados nessa questão são relacionados à criatividade e ao trabalho em equipe, pois essa atividade exige que os alunos usem a imaginação para criar um projeto diferente e atrativo sobre os conceitos da disciplina, e maior interação entre o grupo, para que tudo saia conforme planejado. Esse lado lúdico, a possibilidade de expressão e a motivação, apresentados nos relatos coletados na questão $\mathrm{H}$, são corroborados pelos os achados de Malheiros et al. (2016).

Na pergunta I, Tabela 4, perguntou-se aos estudantes quais os pontos positivos da aplicação da atividade Teoria em Cena na disciplina de Teoria da Contabilidade. Foi possível verificar que os pontos positivos mais apreciados pelos estudantes foram em relação à autoaprendizagem; ao planejamento estratégico do grupo; ao desenvolvimento da criatividade e da oratória; à interação entre a equipe; ao dinamismo da atividade; aos pontos destacados no vídeo; que fazem lembrar do assunto abordado com maior facilidade; e à troca de conhecimentos. Tais pontos podem ser exemplificados por meio das narrativas "faz acontecer o auto aprendizado com a pesquisa em campo", e "Para a aplicação da matéria pode ser positivo, pois os alunos precisam obrigatoriamente pesquisar, ler e estudar para a apresentação". Esses relatos reforçam os resultados encontrados por Engin (2014), de que a atividade de produção de vídeos proporciona a autoaprendizagem e faz com que os alunos busquem sua própria compreensão do tema. 
Os alunos acentuaram, da mesma forma, como fatores benéficos, a inovação didático-metodológica: "é um trabalho diferente do que estamos acostumados a fazer", e "é uma maneira diferente de aprender, melhor do que teoria, slides, etc.". Outro ponto importante observado foi em relação ao volume de conteúdos teóricos na disciplina de Teoria da Contabilidade, em que os alunos acreditam que a atividade Teoria em Cena ajuda na compreensão da disciplina e facilita o entendimento dos conteúdos, convergindo com as visões de Campos et al. (2015) e de Machado et al. (2012) de que conteúdos muito teóricos precisam ser abordados de forma menos cansativa e mais motivadora.

Essa ideia é também reforçada pelos depoimentos dos estudantes: "Método dinâmico de aprendizado, por se tratar de uma disciplina muito teórica, a aplicação da atividade facilita o entendimento e a fixação do conteúdo", e outro, por sua vez, cita: "O fato de abordar essa matéria, que é muito teórica, em forma de trabalho em vídeo é interessante para chamar mais atenção dos alunos para o conteúdo da disciplina", ressaltando, também, as funções didáticas do método destacadas por Malheiros et al. (2016).

$\mathrm{Na}$ última questão discursiva J, ilustrada na Tabela 4, solicitou-se que os estudantes registrassem suas críticas e sugestões para as próximas versões da atividade. A crítica mais citada por todos os alunos foi em relação à escolha dos grupos, a qual foi efetuada por meio de sorteio. É possível perceber que os estudantes não gostaram da estratégia de escolha dos grupos por meio de falas como: "O maior problema foi o grupo ser escolhido pela professora" e "Poderia ser melhor se pudéssemos escolher o próprio grupo".

Percebe-se que os alunos se sentiriam mais à vontade se pudessem escolher o próprio grupo, pois, certamente, escolheriam pessoas com quem têm mais intimidade e afinidade. Esse fato pode apontar para uma limitação de conviver ou trabalhar em equipe com pessoas de fora do núcleo de convívio, dificuldade que, normalmente, ocorre na vida prática profissional. Assim, a produção de atividades desse tipo na graduação pode antecipar o cenário mercadológico empresarial de convívio e realização de atividades com quem não se tem afinidade. Apesar disso, outros estudantes alegaram que a escolha dos grupos efetuada pelo professor instigou a interatividade entre aqueles com quem não tinham muito contato, e isso aumentou o comprometimento com o grupo para que não houvesse discórdia.

Conclui-se, por meio das falas dos alunos e das habilidades despertadas no decorrer da atividade, que esse método é benéfico tanto para a disciplina de Teoria da Contabilidade, quanto para a experiência dos estudantes com mecanismos de aprendizagem ativa, de trabalho em equipe, organização, liderança e criatividade.

\subsection{Autoavaliação}

Na Tabela 11, são ilustradas as respostas dos estudantes para as nove questões de autoavaliação.

Tabela 11:

Autoavaliação dos discentes no desempenho da atividade

\begin{tabular}{|c|c|c|c|c|c|c|}
\hline Pergunta & Média & Mediana & Máximo & Mínimo & Moda & Desvio Padrão \\
\hline Relacionamento com o grupo & 7,91 & 8 & 10 & 1 & 10 & 2,08 \\
\hline Leitura Individual Extraclasse & 7,55 & 8 & 10 & 1 & 8 & 2,23 \\
\hline Busca por Materiais Complementares & 7,64 & 8 & 10 & 1 & 8 & 2,10 \\
\hline Proatividade & 7,86 & 8 & 10 & 3 & 8 & 1,62 \\
\hline Comprometimento com o Grupo & 9,05 & 10 & 10 & 3 & 10 & 1,35 \\
\hline Tempo Para a Atividade & 6,83 & 7 & 10 & 2 & 7 & 2,01 \\
\hline Consulta aos Monitores, Professores e Mestrandos & 4,08 & 4 & 10 & 1 & 1 & 2,94 \\
\hline Visão no Todo do Trabalho & 7,22 & 8 & 10 & 1 & 8 & 2,39 \\
\hline Participação na Realização do Trabalho & 8,97 & 10 & 10 & 1 & 10 & 1,75 \\
\hline
\end{tabular}

Fonte: elaborado pela autora. 
$\mathrm{Na}$ autoavaliação dos estudantes, o desempenho relacionado ao comprometimento com o grupo, o envolvimento na realização de todas as etapas e atividades do trabalho e o relacionamento com a equipe ocupam as três primeiras posições. Isso reforça os indícios de que a produção de vídeos fez com que os estudantes tivessem maior interação com os colegas de sala e se dedicassem à realização da tarefa.

Por ser uma atividade em que o aluno vai explicar um conteúdo, é necessário que ele busque por materiais referentes ao assunto abordado e estude para repassar seu conhecimento à turma. Nesse sentido, observa-se que eles se empenharam, também, com a leitura individual extraclasse e a busca por materiais complementares.

Percebe-se, da mesma forma, que houve proatividade, ou seja, os alunos tiveram que se esmerar para solucionar problemas inesperados. Além disso, dedicaram-se em ficar por dentro da atividade, em seu todo, participando das etapas desenvolvidas e dispensaram tempo para execução da tarefa. Pode-se notar, por meio da Tabela 11, que os estudantes não fizeram muito o uso do atendimento extraclasse com monitores, professores e mestrandos (questão 7), pois a média de nota foi de 4,08, sendo que a nota mais repetida (moda) foi 1 (um).

\section{Considerações Finais}

O objetivo geral do estudo foi analisar a percepção dos alunos quanto à utilidade da produção de vídeos no processo de ensino-aprendizagem da disciplina Teoria da Contabilidade. Participaram da pesquisa 65 alunos de duas turmas que cursavam o sexto período no segundo semestre letivo de 2015.

Os resultados permitiram supor que os alunos gostaram de realizar a atividade e que esta apresenta grande valia como mecanismo de ensino-aprendizagem, pois, quando criam vídeos, os estudantes exercitam e desenvolvem habilidades de leitura, de interatividade; de organização em grupo; e de autoaprendizagem; buscam soluções para questões inesperadas; formas diferentes de exposição do conteúdo; melhoram a oratória e a capacidade de desenvolverem planejamento e liderança; e dedicam-se ao projeto. Por isso, $72 \%$ dos alunos recomendam que a atividade continue a ser aplicada na disciplina Teoria da Contabilidade.

A disciplina de Teoria da Contabilidade é essencialmente teórica, e a atividade Teoria em Cena fez com que os alunos saíssem da rotina de agentes passivos e passassem a explorar os conteúdos por si só, exercitando a aprendizagem ativa, o que desperta a criatividade e a empolgação, fazendo-os usarem a imaginação para explicaram o conteúdo no formato de jornal e teatro, apresentados por meio dos vídeos. A atividade é metodologicamente diferente do formato tradicional de ensino, o que desperta o engajamento dos estudantes em pesquisar por novas ideias e a responsabilidade em elaborar um projeto.

O tamanho da amostra não permite a generalização dos resultados. No entanto, espera-se que os resultados desta pesquisa possam servir de estímulo para que outros professores se encorajem a inovar em seus processos de ensino-aprendizagem, por meio da estratégia da produção de vídeos pelos estudantes.

Esta pesquisa contribui a estudantes, por mostrar que, quando eles se envolvem, profundamente, em processos de promoção da aprendizagem por meio de metodologias ativas, são percebidos ganhos superiores do que aqueles obtidos nos métodos tradicionais de ensino, baseados em aulas expositivas, tais como: maior interação entre pares; melhoria da comunicação oral; organização, planejamento e liderança; e criatividade e responsabilidade pelo próprio aprendizado. Além disso, a produção de vídeos facilita a absorção e a aprendizagem de conteúdos teóricos, de forma leve e descontraída.

Aos professores, os benefícios estão ligados ao fato de que, ao aplicarem mecanismos de ensino-aprendizagem focados no estudante, são alcançados níveis de envolvimento com a disciplina e com o conteúdo que, por vezes, não são conseguidos com aqueles centrados no professor. Ademais, a estratégia pode ser aproveitada, também, em outras disciplinas.

As instituições de ensino se aproveitam dos resultados desta pesquisa ao notarem que são necessárias mudanças no processo formativo, que, atualmente, centra no docente, deslocando-o para o discente, o que, tem revelado consequências expressivamente positivas. Outrossim, para que mudanças efetivas ocorram nos processos educacionais, são necessárias mudanças estruturais, de formação docente e de investimentos em tecnologias, basicamente. 
Para futuras pesquisas, sugere-se ampliar a amostra, bem como verificar qual a opinião dos professores sobre esse método. Do mesmo modo, seria oportuno investigar se a produção de vídeos ajuda na formação de futuros profissionais da educação a distância.

\section{Referências}

Almeida, A. C. P. (2013). Produção de vídeos em sala de aula: Uma proposta de uso pedagógico de celulares e câmeras digitais. Revista de Educação, Ciência e Tecnologia, 2(1), pp.1-13.

Campos, L. C., Machado, T. R. B., \& Rech, I. J. (2015). O ensino da teoria da contabilidade em cursos de graduação e em cursos de pós-graduação stricto sensu no Brasil. Congresso UFU de Contabilidade, 1, pp. 1- 13. Uberlandia, MG, Brasil. Recuperado em 10 janeiro, 2016, de http://www.cont.facic.ufu. br/sites/cont.facic.ufu.br/files/5-2980-2981_ensino_de_teoria_da_contabilidade.pdf.

Conselho Federal de Contabilidade - CFC. (1992). Resolução CFC n. 732. Aprova a NBC T 4 - da Avaliação Patrimonial. Recuperado em 19 novembro, 2015, de http://www.cfc.org.br/sisweb/sre/docs/ RES_732.doc.

Castanha, D., \& Castro, M. B. (2010). A necessidade de refletir sobre as estratégias pedagógicas para atender à aprendizagem da geração Y. Revista de Educação do Cogeime, 19(36), pp.27-38.

Costa, P. S., Santana, M. E. G., Brounbeck, G., \& Gomes, G. S. (2016). Um safari no Brasil: evidências sobre o ensino baseado na estrutura conceitual. Congresso USP de Controladoria e Contabilidade, 16, São Paulo, SP, Brasil. Recuperado em 20 janeiro, 2016, de http://congressousp.fipecafi.org/arquivos/ TrabalhosAprovados-2016-pdfs/201.pdf.

Dahawy, K., Tooma, E., \& Kamel, S. (2005). The use of IT in teaching accounting in Egypt: The case of Becker Conviser. Journal of Communications of International Information Mangement Association, 5(3), pp. 25-34.

Engin, M. (2014). Extending the flipped classroom model: Developing second language writing skills through student- created digital videos. Journal of the Scholarship of Teaching and Learning, 14(5), pp. 12-26. doi: https://doi.org/10.14434/josotlv14i5.12829

Fávero, L. P., Belfiore, P., Silva, F. D., \& Chan, B. L. (2009). Análise de dados: modelagem multivariada para tomada de decisões. Rio de Janeiro: Elsevier.

Goode, J. (2010). The digital identity divide: how technology knowledge impacts college students. New Media \& Society, 12(3), pp. 497-513.

Holtzblatt, M., \& Tschakert, N. (2011). Experiential learning via an innovative inter-university IFRS student video competition. Accounting Education: an international journal, 20(4), pp. 349-372. doi: http://dx.doi.org./10.1080/09639284.2010.515717

Leal, D. T. B., \& Cornachione Júnior, E. (2006). A aula expositiva no ensino da contabilidade. Contabilidade Vista \& Revista, 17(3), pp. 91- 113.

Machado, M. H., Vieira, V. S., \& Meirelles, R. M. S. (2012). Uso do vídeo no ensino de biologia como estratégia para discussão e abordagens de temas tecnológicos. III Encontro Nacional de Ensino de Ciências da Saúde e do Ambiente, 3, Rio de Janeiro, RJ, Brasil. Recuperado em 23 dezembro, 2015, de http://ivenecienciassubmissao.uff.br/index.php/ivenecienciassubmissao/eneciencias2012/paper/ download/341/212.

Malheiros, R., Lima, R. L., \& Mariani, R. (2016). Videoprocesso: Ferramenta de Equidade no Ensino. Journal of Research in Special Educational Needs, 16(S1), pp. 1085-1089. doi: http://dx.doi. org./10.1111/1471-3802.12253. 
Marshall, J. M. (2002). Learning with technology: evidence that technology can, and does, support learning. San Diego State University. Recuperado em 15 novembro., 2015, de https://www.dcmp.org/caai/ nadh176.pdf.

Martin, E., Evans, P., \& Foster, E. (1995). The use of videos in the teaching of accounting. Accounting Education, 4(1), pp. 77-86. doi: http://dx.doi.org./10.1080/09639289500000008.

Neves Júnior, I. J., \& Rocha, H. M. (2010). Metodologias de ensino em contabilidade: uma análise sob a ótica dos estilos de aprendizagem. Encontro da ANPAD - ENANPAD, 34. Rio de Janeiro, RJ, Brasil. Recuperado em 10 novembro, 2015, Rio de http://www.anpad.org.br/admin/pdf/epq1975.pdf.

Pereira, M. V., \& Rezende Filho, L. A. C. (2013). Investigando a produção de vídeos por estudantes de ensino médio no contexto do laboratório de física. Revista Tecnologias na Educação, Rio de Janeiro, 5(8), pp.1-12.

Sargent, C. S., Borthick, A. F., \& Lederberg, A. R. (2011). Improving retention for principles of accounting students: Ultra-Short online tutorials for motivating effort and improving performance. Issues in Accounting Education, 26(4), pp. 657-679.

Silva, R. V., \& Oliveira, E. M. (2010). As possibilidades do uso do vídeo como recurso de aprendizagem em salas de aula do $5^{\circ}$ ano. Encontro de Pesquisa em Educação em Alagoas - EPEAL, 5, Maceió, AL, Brasil. Recuperado em 12 novembro, 2015, de http://www.seer.ufs.br/index.php/edapeci/article/ view/602/506.

Vargas, A., Rocha, H. V., \& Freire, F. M. P. (2007). Promídia: produção de vídeos digitais no contexto educacional. RENOTE - Revista Novas Tecnologias na Educação, 5(2), pp. 1- 13.

Weil, S., Laswad, F., Frampton, C., \& Radford, J. (1999). Cultural and other influences on student perceptions of the use of case studies and study groups in management accounting. Discussion Paper № 62, Commerce Division, Lincoln University, New Zeland.

Weil, S., Oyelere, P., Yeoh, J., \& Firer, C. (2001). A study of students' perceptions of the usefulness of case studies for the development of finance and accounting-related skills and knowledge. Accounting Education, 10(2), pp. 123-146. doi: 10.1080/09639280110081642.

\section{Apêndice A - Questionário de Avaliação - Teoria em Cena}

O presente questionário tem como objetivo identificar a percepção dos alunos sobre o projeto Teoria em Cena. As respostas dadas são confidenciais e servirão para o aprimoramento didático, bem como para a avaliação de sua eficácia como instrumento de ensino. Além disso, permitirá verificar se os objetivos de aprendizagem propostos pela atividade foram cumpridos.

Por favor, não deixe nenhuma questão sem resposta. Sua opinião é muito importante.

Obrigada pela sua colaboração!

\section{CARACTERIZAÇÃO DO RESPONDENTE}

Nome:

Idade:__ (em anos) Período Regular:

Turno: ( ) Integral ( ) Noturno Gênero: ( ) Feminino ( ) Masculino

Estado Civil: ( ) Solteiro ( ) Casado ( ) Viúvo ( ) Separado

Trabalha: ( ) Sim ( ) Não

É a primeira vez que você está cursando a disciplina de Teoria da Contabilidade? ( ) Sim （ ) Não 


\section{TEORIA EM CENA}

As questões a seguir referem-se à sua percepção sobre a atividade de Teoria em Cena realizada durante a disciplina de Teoria da Contabilidade. O objetivo deste questionário é avaliar sua opinião sobre a utilidade do uso de vídeos como um método de ensino-aprendizagem.

Indique seu grau de concordância com cada uma das questões abaixo, atribuindo nota de 1 a 10, sendo a nota 1: total DISCORDÂNCIA e a nota 10: total CONCORDÂNCIA com cada questão.

\begin{tabular}{l}
\hline \multicolumn{1}{c}{ Considero que o desenvolvimento do Projeto Teoria em Cena ... } \\
\hline facilitou o entendimento da disciplina \\
\hline fez com que eu estudasse mais para desenvolver o projeto \\
\hline proporcionou maior aplicação dos conceitos teóricos \\
\hline a atividade contribuiu significativamente para meu melhor desempenho na disciplina \\
\hline despertou maior interesse pela disciplina \\
\hline consegui ampliar meus conhecimentos \\
\hline me tornei-me mais criativo após o desenvolvimento do projeto \\
\hline favoreceu uma maior interação entre meus colegas de sala \\
\hline os resultados do trabalho foram melhores por terem sido desenvolvidos em grupo \\
\hline potencializou minhas habilidades de trabalhar em equipe \\
\hline melhorou minha habilidade de comunicação \\
\hline fez com que eu desenvolvesse minha capacidade de usar novas tecnologias \\
\hline ajudou-me a desenvolver minha habilidade para resolução de problemas \\
\hline ajudou-me a desenvolver minhas habilidades de liderança \\
\hline ajudou-me a desenvolver minhas habilidades de planejamento \\
\hline me senti motivado e entusiasmado em participar desta atividade \\
\hline considero que o projeto é adequado para a disciplina \\
\hline o método contém obstáculos difíceis de vencer \\
\hline fiquei satisfeito com os resultados ao término da atividade \\
\hline o método é dinâmico \\
\hline proporciona a auto-aprendizagem \\
\hline
\end{tabular}

Se eu tivesse oportunidade, eu faria essa atividade novamente? ( ) SIM （ ） NÃO

Você foi um dos personagens do vídeo do seu grupo? ( ) SIM （ ） NÃO

Em caso positivo, você se sente mais desinibido sendo filmado ou apresentando trabalhos pessoalmente em sala de aula? Por favor, comente.

Qual nota você atribui para a utilização de vídeos como estratégia de ensino-aprendizagem? (atribua uma nota entre 1 e 10)

Qual nota você atribui para a atividade de Teoria em Cena no processo de ensino-aprendizagem na disciplina de Teoria da Contabilidade?

(atribua uma nota entre 1 e 10) 
Você recomenda que a atividade de Teoria em Cena continue a ser aplicada na disciplina de Teoria da Contabilidade?

(atribua uma nota entre 1 e 10)

Em caso negativo, justifique a sua resposta:

Em sua opinião, outros benefícios além dos apresentados na sessão anterior do questionário podem ser conseguidos com a aplicação da atividade de vídeos? Se sim, quais?

Em sua opinião, quais os pontos positivos da aplicação da atividade de Teoria em Cena na disciplina de Teoria da Contabilidade?

Esse espaço é seu! Aproveite e registre suas críticas e sugestões para que possamos aprimorar as próximas versões desta atividade.

Faça uma autoavaliação, atribuindo nota de 1 a 10 para o seu desempenho nos quesitos abaixo. Estas respostas contribuirão para percebermos as relações entre as ferramentas utilizadas e a sua real contribuição para o desempenho dos estudantes.

Item para autoavaliação

Nota de 1 a 10

Integração e relacionamento com o grupo

Leitura individual extraclasse

Busca por materiais complementares

Pró-atividade

Comprometimento com as minhas atribuições no grupo

Tempo disponibilizado para a atividade

Uso de atendimento extraclasse aos monitores, professores e mestrandos

Tive uma visão do todo no trabalho

Participei da realização de todas as etapas e atividades do trabalho 